\title{
SISTEM MONITOR TEKANAN DARAH ARTERI PADA LENGAN DENGAN METODE NMR (DALAM BENTUK MODEL)
}

\author{
Bambang Murdaka Eka Jati ${ }^{1}$, Kusminarto ${ }^{1}$, Agung Bambang SU ${ }^{1}$, Bambang Irawan ${ }^{2}$ \\ ${ }^{1}$ Jurusan Fisika, Fakultas MIPA, UGM,Jogjakarta, Indonesia \\ ${ }^{2}$ Klinik Jantung Terpadu, RSU Dr. Sardjito,Jogjakarta, Indonesia \\ Email: b_murdaka@ugm.ac.id
}

\begin{abstract}
Abstrak - Telah dilakukan penelitian yang bertujuan untuk membuat sebuah model alat pemantau tekanan darah arteri pada lengan manusia, dengan metode NMR. Penelitian dilakukan dengan menempatkan pipa plastik (berdiameter 0,5 cm) datar

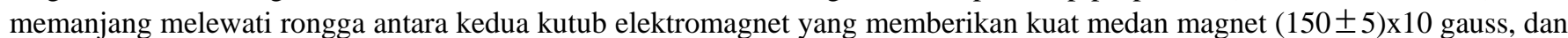
juga berada di sepanjang koil $R F$. Disamping koil $R F$ itu terdapat pula koil penerima. Saat itu, air mengalir di dalam pipa pada kelajuan $(4 \pm 1) 10^{-1} \mathrm{~m} / \mathrm{s}$ yang bersesuaian dengan tekanan $80 \mathrm{~N} / \mathrm{m}^{2}$. Penelitian ini dilandasi oleh kenyataan bahwa $80 \%$ darah berupa air, dan molekul air mengandung atom hidrogen yang di dalam atomnya terdapat proton. Model ini dilandasi oleh kenyataan bahwa kelajuan alir darah di pembuluh arteri pada lengan $(5 \pm 1) \times 10^{-1} \mathrm{~m} / \mathrm{s}$, dan diameter pembuluh darahnya juga 0,4 cm. Penelitian ini berhasil memberikan informasi, bahwa aliran air di dalam pipa plastik pada kelajuan, tekanan, dan kuat medan magnet di atas mampu memberikan frekuensi resonansi $N M R$ sebesar 5,5MHz, dan koil penerima memberikan GGL induksi di CRO sebesar $18 \mathrm{mV}$.
\end{abstract}

Kata-kata kunci: $N M R$, tekanan, air-darah, pipa pembuluh darah

\section{PENDAHULUAN}

Penelitian ini dilatarbelakangi oleh semakin diperlukannya variasi alat kesehatan baik terkait jenis maupun metodenya. Itu diperlukan karena kesadaran masyarakat untuk memantau perkembangan kesehatannya, bagi masyarakat kelas menengah ke atas, sudah semakin besar. Terkait hal itu, masyarakat memerlukan informasi dini yang kuantitatif dan terpercaya dari parameter kesehatannya. Salahsatu informasi dini yang diperlukan terkait kesehatan adalah alat pemantau tekanan darah. Nilai tekanan darah berkaitan erat dengan penyakit yang bersifat tidak menular tetapi mematikan (misal jantung koroner) dan juga membuat organ tidak berfungsi (misal stroke) [1]. Sementara itu, produk penelitian teknologi kesehatan yang dilakukan oleh dokter masih sedikit. Artinya, penelitian yang terkait produk teknologi kesehatan beserta modelnya yang berbasis fisika perlu dilakukan juga oleh fisikawan.

Terkait keberadaan alat pemantau tekanan darah, sekarang ini, sudah dijumpai beragam metode pengukuran tekanan darah, baik secara non invasif (alat di luar organ) maupun invasif (alat di dalam organ). Metode pemantauan tekanan darah secara non invasif yang paling populer saat ini adalah Sphygmomanometer, dan dikembangkan secara elektronik pada ibujari pasien [2,3,4]. Metode ini praktis, namun memberikan ralat besar (orde 10\%) sehingga hanya baik untuk pemantau tekanan darah bagi orang sehat. Metode invasif dilakukan dengan memasukkan sensor tekanan pada pembuluh darah pasien. Metode ini tidak praktis, tetapi lebih presisi dan cocok untuk diterapkan pada pasien yang sakit keras. Selanjutnya, perlu diperkenalkan metode pemantau tekanan darah yang lain, bersifat non invasif, dalam keadaan darah mengalir, walau demikian yang dikerjakan penulis masih dalam bentuk modelnya.

Penelitian ini bertujuan untuk dapat membuat model alat pemantau tekanan darah berbasis NMR (Nuclear Magnetic Resonance). Selain itu, tekanan darah yang dipantau dalam keadaan tanpa hambatan. Model alat pemantau tekanan darah itu berupa air yang dialirkan pada pipa kecil yang dilewatkan antara 2 kutub elektromagnet dan melewati sepanjang sumbu koil RF (radio frequency) [5].

Sesuai dengan dasar layanan Perguruan Tinggi (PT), yakni Tri Dharma PT, penelitian ini memberikan 3 manfaat, yaitu untuk: Pendidikan dan Pengajaran (Dikjar), Penelitian (LIT), dan pengabdian kepada masyarakat (PkM). Bagi Dikjar, dapat diperoleh pengetahuan baru bahwa NMR bersifat prospektif untuk pemantau tekanan darah. Bagi LIT, dapat memberikan pengalaman penulis dalam penelitian bidang tersebut. Bagi $\mathrm{PkM}$, prospektif diperoleh alat pemantau tekanan darah berbasis NMR yang dapat memberikan kesejahteraan bagi produsen dan pemakainya.

\section{METODE PENELITIAN}

Penelitian ini menggunakan bahan air dan pipa plastik. Air disetarakan dengan darah (yang dimodelkan), sedangkan pipa plastik (tempat air mengalir) disetarakan dengan pembuluh arteri di lengan. Diameter pipa plastik dipilih 0,5 cm dan kelajuan alir air 0,4 m/s yang berturutturut disetarakan dengan diameter pembuluh arteri dan kelajuan darah yang mengalir di lengan. Bahan lain yang dipakai adalah kawat koil yang digunakan untuk membuat koil $R F$ dan koil penerima (receiver coil) atau koil $R C$, serta sejumlah komponen yang digunakan untuk penguat dan 
penyearah arus listrik sehingga diperoleh arus searah $(D C)$ maksimum 10 ampere.

Adapun alat yang digunakan adalah sistem elektromagnet (penghasil medan magnet 1500 gauss menggunakan DC sebesar 4 ampere), function generator atau FG (pemberi sinyal pada koil $R F$ ), dan $C R O$ (penangkap sinyal $N M R$ dari koil $R C$ ). Selain itu, digunakan pula teslameter yang berguna untuk mengukur kuat medan magnet dan homogenitasnya di ruang antara kutub utara $(U)$ dengan kutub selatan $(S)$. Set-up eksperimen pada penelitian ini diperlihatkan pada Gambar 1, potretnya ditampilkan pada Gambar 2, sedangkan eksperimen (prospektif) yang dimodelkan ditampilkan pada Gambar 3. Adapun set-up eksperimen tahap akhir (direncanakan) diperlihatkan pada Gambar 4.

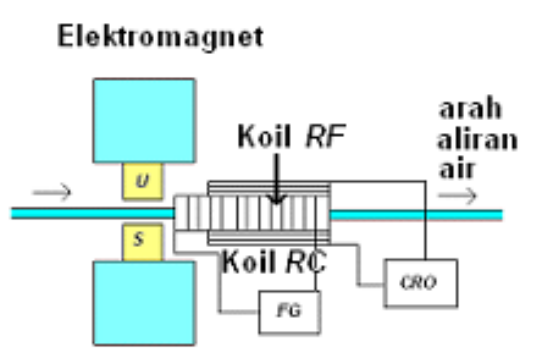

Gambar 1. Bagan eksperimen model pada penelitian ini.

Munculnya sinyal $N M R$, pada penelitian ini, dilandasi oleh keberadaan momen dipol magnet spin proton atom

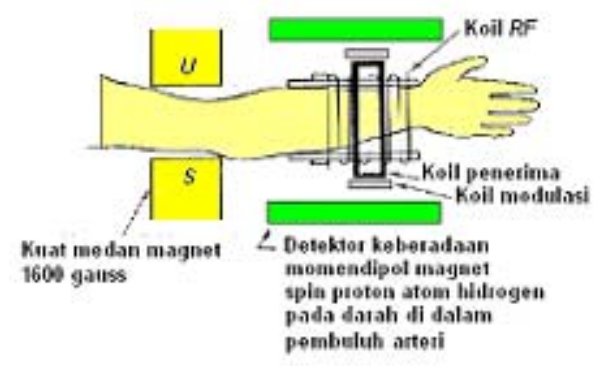

Gambar 3. Pola eksperimen yang dimodelkan.

hidrogen (mdmspah) yang berada di dalam molekul air. Semula, mdmspah (di dalam air yang mengalir) berarah acak (Gambar 5a). Kemudian, ketika berada di antara 2 kutub elektromagnet $(U-S)$ maka mdmspah pun berorientasi sejajar kutub $U-S$ (Gambar 5.b) [6]. Setelah melewati kutub $U-S$, mdmspah menderita radiasi gelombang elektromagnetik dari koil $R F$ yang terhubung dengan $F G$ sehingga mdmspah pun tereksitasi (Gambar 5c). Setelah tereksitasi selama waktu relaksasinya (longitudinal $T_{1}$, dan transversal $T_{2}$ ) maka arah mdmspah pun kembali berarah acak (Gambar 5.d). Diketahui, untuk air $T_{1}=T_{2}=2,5 \mathrm{~s}$, sedangkan untuk darah $T_{1}=0,8 \mathrm{~s}$ dan $T_{2}=0,1 \mathrm{~s}$ [7]. Adanya peristiwa Gambar 4c ke Gambar 4d menyebabkan adanya perubahan fluks medan magnet yang ditangkap oleh koil $R C$, dan memberikan GGL induksi yang bisa dibaca pada layar CRO. Tentusaja, GGL induksi itu semakin besar bila jumlah mdmspah yang tereksitasi lebih banyak, dan juga kelajuan $(v)$ alir air (berarti pula nilai tekanannya $P$ ) lebih besar. Jika massa jenis air tersebut $\rho$, maka pada pipa plastik yang

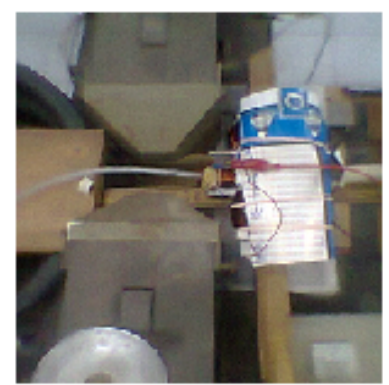

Gambar 2. Potret eksperimen model pada penelitian ini.

datar memberikan hubungan antara $P$ terhadap $v$ dalam bentuk $P=\frac{1}{2} \rho v^{2}$.

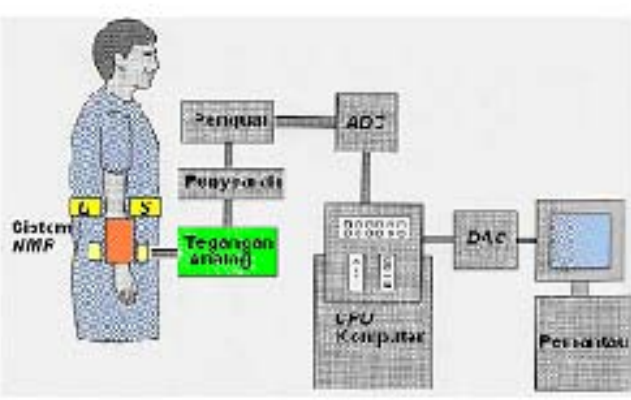

Gambar 4. Bagan kerja alat kesehatan yang direncanakan. 


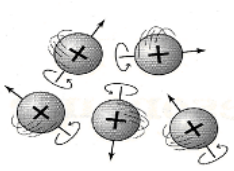

(a)

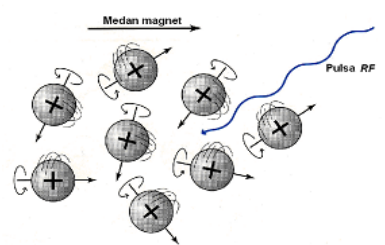

(c)

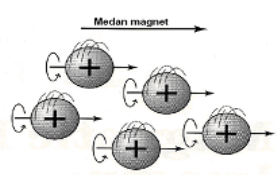

(b)

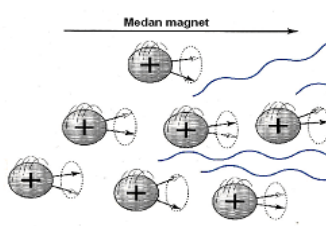

(d)
Gambar 5 Transisi mdmspah di dalam molekul air: (a) arah acak, (b) terorientasi sejajar kutub $U-S$ elektromagnet, (c) tereksitasi, dan (d) berarah acak kembali.

\section{HASIL PENELITIAN DAN PEMBAHASAN}

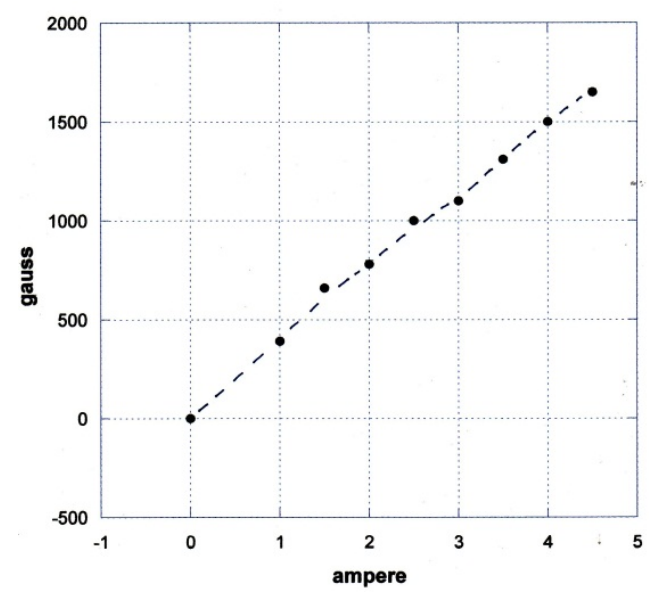

Gambar 6 Kuat medan magnet di pertengahan antara kedua kutub elektromagnet sebagai fungsi arus listrik yang dialirkan.

Setelah dilakukan metode penelitian, akhirnya dapat diperoleh sejumlah hasil eksperimen, dan hasil itu ditampilkan pada Gambar 6, 7, dan 8. Diperoleh informasi karakter kuat medan magnet yang berada di antara kedua kutub elektromagnet $\left(B_{o}\right)$ sebagai fungsi $D C$ (i) yang dialirkan pada koil elektromagnet. Hubungan itu $($ a) diperlihatkan pada Gambar 6, bahwa $B_{o}$ adalah fungsi linear terhadap $i$. Berhubung, secara teori, sinyal NMR baru bisa dilihat pada $B_{o}>100$ gauss dan $B_{o}$ harus stabil, maka pada penelitian ini menggunakan $i=4$ ampere yang bersesuaian dengan $B_{o}=1500$ gauss. Sementara itu, $i=4,5$ ampere (bersesuaian dengan $B_{o}=1700$ gauss) pada penelitian ini tidak dipilih sebab $B_{o}$ bersifat tidak stabil. Setelah sistem model peralatan pemantau tekanan darah arteri lengan (Gambar 1 dan 2) dioperasikan pada $i=4$ ampere, kelajuan alir air $(4 \pm 1) 10^{-1} \mathrm{~m} / \mathrm{s}$, dan berhasil memberikan sinyal NMR (berupa GGL induksi sebesar $18 \mathrm{mV}$ ) pada frekuensi resonansi NMR ( $v)$ 5,5 MHz (Gambar 7). Hasil itu konsisten dengan nilai referensi pada proton atom hidrogen, yaitu: $\left(\frac{v}{B_{o}}\right)=42,6(\mathrm{MHz} / 10.000$ gauss).

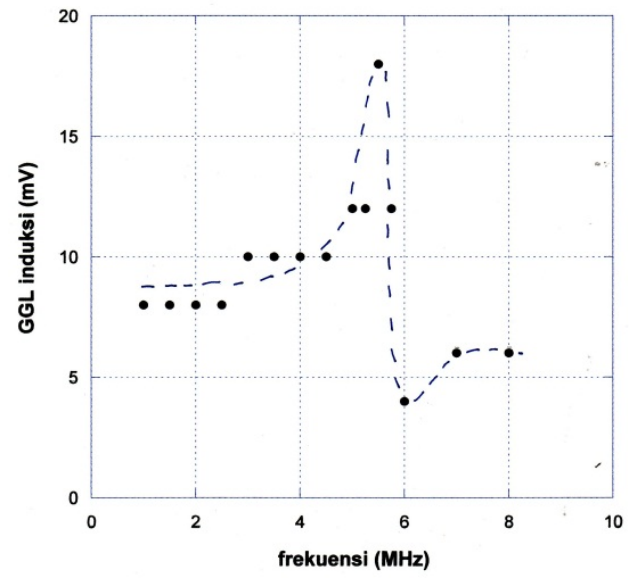

Gambar 7 Frekuensi resonansi sinyal NMR yang memberikan GGL induksi terbesar (18 mV)

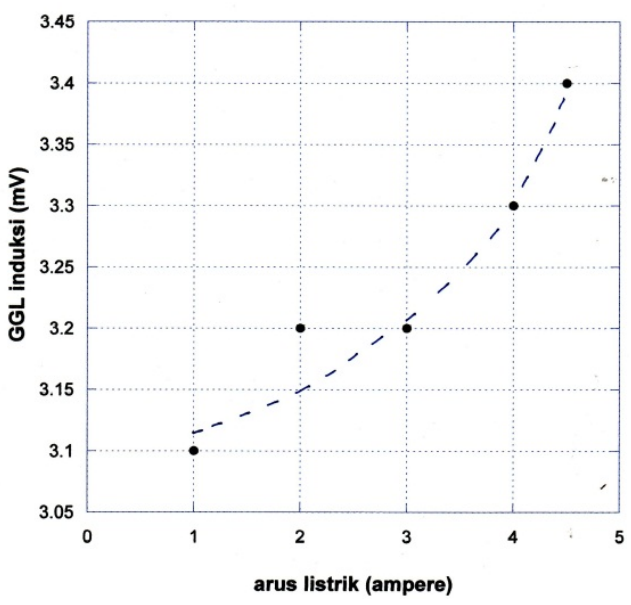

Gambar 8. GGL induksi membesar ketika $B_{0}$ membesar, sehingga populasi spin turah mdmspah juga menjadi lebih besar.

Diperoleh peningkatan sinyal $N M R$ bila $B_{o}$ diperbesar. Gambar 8 memperlihatkan hubungan antara GGL induksi dengan $B_{o}$ (dinyatakan oleh variasi nilai $i$ ). Bertambahnya GGL induksi oleh bertambahnya $B_{o}$ menunjukkan bahwa populasi spin turah pada selisih antara populasi mdmspah aras atas $\left(n_{1}\right)$ dengan bawah $\left(n_{2}\right)$ pun meningkat. Ini konsisten dengan tinjauan secara kuantum, pada suhu sampel (air mengalir) $T$, dan tetapan (giromagnet 
$\gamma$, plank $h$, dan stefan - boltzman $k$ ), dipenuhi: $\Delta n=\left(n_{2}-n_{1}\right)=\frac{\not h B_{o}}{2 \pi k T}$.

\section{SIMPULAN}

Sinyal NMR dapat dihasilkan dari air mengalir berkelajuan $(4 \pm 1) 10^{-1} \mathrm{~m} / \mathrm{s}$ pada tekanan $80 \mathrm{~N} / \mathrm{m}^{2}$ di dalam pipa berdiameter $0,5 \mathrm{~cm}$ yang melewati ruang di antara 2 kutub elektromagnet yang memberikan kuat medan magnet (150土5)10 gauss. Selanjutnya, frekuensi gem-nya 5,5 MHz, dan sinyal NMR itu berupa GGL induksi sebesar $18 \mathrm{mV}$. Hasil penelitian ini, memberi inspirasi bahwa sinyal NMR oleh aliran darah arteri lengan manusia dapat pula diperoleh dengan menggunakan perangkat eksperimen yang telah dikerjakan oleh penulis.

\section{UCAPAN TERIMAKASIH}

Penulis ucapkan terimakasih kepada "Proyek Penelitain Kecil” di Lab Atom dan Inti, Jurusan Fisika di FMIPA UGM, yang telah mendanai penelitian ini.

\section{DAFTAR PUSTAKA}

[1] Brown, B.H., Smallwood, R.H., Barber, D.C., Lawford, P.V., Hose,D.R., 1999: Medical Physics and Biomedical Engineering, IOP Publishing Ltd, London.
[2] Jati, B.M.E., Kusminarto, Bambang, A., Irawan, B.; 2010: Karakterisasi Koil Penerima dan Koil RF pada Pembuatan Sistem Monitor Tekanan Fluida Mengalir Berbasis Metode NMR, Volume 4 Proceeding Book, $7^{\text {th }}$ Basic Science National Seminar, Unibraw, Malang.

[3] Friedman, B.H.; Christie, I.C.; Sargent, S.L.; Weaver, B.J., 2004: Self-reported sensitivity to continous non invasive blood pressure monitoring via the radial artery, Journal of Psychosomatic Research, Vol. 57, p.119- 121 .

[4] Lewis, G.; Gona, P.; Larson, M.; Piehn, J.F.; Benyamin, E.J.; Donnell, C.J.; Levy, D.; Vasan, R.S.; Wang, T.J., 2008: Exercise Blood Pressure and the Risk of Incident Cardiovascular Disease (from the Framingham Heart Study), The American Journal of Cardiology, Vol. 101, p. $1614-1620$.

[5] O’Brien, T.; O’ Malley, K.; 1979: ABC of Blood Pressure Measurement, Britis Medical Journal, London.

[6] Yarows, S.A.; Patel, K.; Brook, R.; 2001: Rapid Oscillometric Blood Pressure Measurement compared to Conventional Oscillometric Measurement, Blood Pressure Monitoring, Vol. 6 No. 3, p. 145 - 147, Lippincott \& Wilkin, Michigan.

[7] Valk, J., MacLean, C., Algra, P.R., 1985: Basic Principles of Nuclear Magnetic Resonance Imaging, Elsevier, Amsterdam 